\title{
The Factors Affecting The Adoption Of LED Lamps
}

\author{
Orose Leelakulthanit, National Institute of Development Administration, Thailand
}

\begin{abstract}
The purpose of this paper is to investigate the factors affecting the intention to buy LED lamps on the part of adult Bangkokians that are the purchase decision-makers and are aware of LED lamps. A multiple regression model was employed to investigate the factors affecting the intention to buy LED lamps. Thirteen motives for adopting LED lamps were identified. They were: price, quality, energy saving, durability, trustworthiness of LED lamp performance, compatibility of LED lamps with the lighting fixtures, brand, product availability, promotion and corporate social responsibility, environmental consciousness, social well-being, and perceived effectiveness of environmental behavior. In addition, the effects of demographic variables (i.e., gender, age, education, and household income) on the adoption of LED lamps were examined. A total of 555 responses were collected from the adult shoppers. The results of the multiple regression analyses suggest that the factors affecting the intention to purchase LED lamps in the low household income segment are quality, compatibility of LED lamps with lighting fixtures, product availability, and corporate social responsibility. In the high household income segment, they are energy saving and perceived effectiveness of environmental behavior.
\end{abstract}

Keywords: Innovation; New Products; LED Lamps; Consumer Behavior

\section{INTRODUCTION}

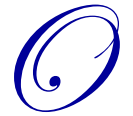

ver the past few years, energy security and sustainable development have become more important in the current global environment. There are two main reasons for this. The first is the impact of high and often volatile energy prices, and the second concerns environmental sustainability-particularly with reference to the global climate. Both issues are critically important for Asia and the Pacific - a region in which impressive economic growth has increased the demand for energy and has placed corresponding strain on the environment. Since 1980, the world has doubled its use of primary energy and much of this increase has come from Asia and the Pacific. This increased use stems from several reasons: rapid economic growth, huge investments in infrastructure and a booming construction industry, an increase in the population, and a decline in the use of noncommercial energy, for example biomass and waste; and this growth is likely to continue. Compared with other parts of the world, this region produces and consumes energy inefficiently and as a result, a viable strategy for energy security and sustainable development must stress measures to reduce the intensive of energy intensity by increasing the efficiency of energy production and its conversion, transmission, and utilization. The region also has to find ways to reduce the impact of energy use on the environment and on the climate. In order to accomplish this, low-carbon energy use must be diversified. This includes the use of natural gas and renewable resources, while at the same time efficiency must be improved by making better use of new and more advanced technologies.

In the rapidly-industrializing, middle-income countries such as Thailand and Malaysia, energy use has grown at a faster rate than the GDP. For this reason, increasing energy efficiency through the use of the most advanced technology (in the context of the present essay, the use of Light Emitting Diode (LED) lamps) is warranted. The residential LED lighting market in 2012 however was low in the Asia-Pacific (8\%) region as compared with other countries and regions, for instance Japan (27\%), Europe (22\%), America (20\%), and China (19\%). In Thailand, the Electricity Generating Authority of Thailand (EGAT) revealed that the country's overall lighting market in 2011 was worth THB7 billion, exhibiting 4\% growth from 2010. LED lighting has a 12\% market share. LED lamps were introduced to the Thai market in 2007, and they are still at a beginning stage of penetration 
in the Thai market. This research is an early attempt to investigate the adoption of LED lamps in the household sector by studying what drives people's intention to buy residential LED lamps.

\section{LITERATURE REVIEW}

\section{Relative Advantage of LED Technology}

Perceived Costs of Using LED Lamps

According to Menanteau and Lefebvre (2000), there has been only partial adoption of Compact Fluorescent Light (CFL) technology for a number of reasons. For example, both CFL and modern LED lamps are characterized by high initial costs for consumers, and this serves as a barrier to their adoption. The price of LED lamps are high compared to CFL lamps and incandescent lamps, given an approximate number of lumens or roughly an equal amount of visible light emitted by them. For example, a well-known brand of LED light with 470 lumens in Thailand costs approximately $\$ 53$, while the CFL lamps of that same brand with 400 lumens cost around $\$ 5$, a substantial difference for the consumer. Further, the incandescent lamps produced by the same brand with 430 lumens cost around $\$ 0.5$. It is therefore likely that the high initial purchase cost of LED lamps will be an obstacle to their adoption; that is to say, price will be negatively related to the intention to buy LED lamps.

\section{Perceived Value and Perceived Benefits of Using LED Lamps}

Generally speaking, perceived value occurs when consumers perceive that an innovation offers greater benefits or lower costs than existing alternatives. In other words, products with high perceived value may be more readily adopted than those with low perceived value. Furthermore, the value of an innovation for the consumer is affected by its perceived relative advantage; that is, the extent to which it is perceived to offer benefits that are superior to those of existing products. In fact, research indicates (Henard \& Szymanski, 2001) that a product's perceived advantage is one of the most important predictors of the success of a new product. Regarding LED lamps, their advantage can be characterized as follows.

\section{Quality}

First, LED lights do not typically burn out in the same way that incandescent bulbs do; instead, they become progressively dimmer over time. Additionally, they do not emit UV or infrared light, produce very little heat, are resistant to shock and vibration, and operate effectively in cold environments, and they contain no mercury. The fact that LEDS reduce the harmful emissions (including mercury) flowing into the environment and eliminate the chance of creating pollution when the bulbs are disposed of is very good news for the environment. It is assumed here then that the higher is the quality of LED lamps, the higher will be their rate of adoption.

\section{Energy Savings}

LED lamps tend to use less than one-sixth as much energy as their incandescent or halogen counterparts, and 2-3 times less than most CFLs. The efficiency of light bulbs can be determined by comparing the amount of light produced to the amount of energy consumed. The goal should be to find a light fixture that emits the most light with the least amount of energy consumed and at the best price for one's budget. However, leaving price aside, research shows that LED light bulbs are the most energy-efficient: LED bulbs produce 90 to 112 lumens per watt; compact fluorescent lamps produce 40 to 70 lumens per watt; and traditional incandescent bulb fixtures only produce 10 to 17 lumens per watt. Consequently, from a purely scientific point of view, LEDs are the most energyefficient bulbs because with proper design, an LED circuit will approach $80 \%$ efficiency. This means that $80 \%$ of the electrical energy is converted to light energy while the remaining $20 \%$ is lost as heat energy. This conversion to light energy can be compared with that of incandescent bulbs, which operate at about $20 \%$ efficiency ( $80 \%$ of the electrical energy is lost as heat). In terms of the environment, this reduction in electricity consumption results in the reduction of greenhouse gas emissions. It is hypothesized here then that energy savings is positively related to the intention to purchase LED lamps. 


\section{Durability}

The useful life of LED lights is based on the number of operating hours until the LED emits $70 \%$ of its initial light output. Top-quality LEDs in well-designed fixtures are expected to have a useful life of 30,000 to 50,000 hours, significantly higher than the 1,000 hours for a typical incandescent bulb, and 8,000 to 10,000 hours for a comparable CFL. The longer the life of LED lamps, the better the return to the consumer of the high initial investment in them, and therefore it is hypothesized that the durability of LED lamps will be positively related to the intention to purchase them.

\section{Trustworthiness of LED Lamp Performance}

LED lamps are relatively new in the market in Thailand; their market share of $12 \%$ indicates that the vast majority of consumers still have not adopted this product, and therefore the majority of consumers do not have direct experience with this product and may have to rely on the information mainly from company advertisements instead of their own experience or information provided by friends and family. Research suggests that people tend not to trust the claim that products are "green" and that this has become an obstacle to their purchase (Mostafa, 2009). Thus, it is assumed that the trustworthiness of LED lamp performance is positively related to the intention to purchase LED lamps.

\section{Compatibility of LED Lamps with Lighting Fixtures}

According to the notion of relative advantage, the perceived value of an innovation will increase if the perceived cost is lower compared to its perceived benefit. The cost of adopting LED lamps is also related to whether consumers have to change their existing lighting fixtures. It follows then that the biggest hurdle to the adoption of LED replacement lamps today is the incompatibility between the lamps and the various fixtures, transformers, and dimmers that in many cases are designed for traditional light sources. This incompatibility can be mechanical; for example, the lamp might not fit the fixture. The incompatibility can also be thermal and electrical: the lamp might overheat or not be compatible with the transformer or dimmer respectively. It is hypothesized then that the higher is the compatibility of LED lamps with the lighting fixtures, the higher will be the intention to purchase LED lamps.

\section{Marketing Factors}

Brand

A brand is more than a product since it satisfies both tangible and intangible needs, and a brand has various elements attached to it, such as symbols, logos, brand association, the brand name, brand awareness, and so forth. At the early stage of the diffusion of an innovation, as in the case of LED lamps, creating brand awareness is very important in terms of securing the adoption of the product. Brand awareness for example can affect the choices that people make among brands even if essentially no other associations obtain with those brands. For example, it has been shown in the research that consumers sometimes have the tendency to purchase products made by only one familiar, well-established brand (Jacoby, Syzabillo, \& Busato-Schach, 1977). Thus in the context of lowinvolvement decisions (as in the case of LED purchases), a minimum level of brand awareness may be sufficient in order for the consumer to make a purchase decision, even when a well-formed attitude does not exist (Bellman \& Park, 1980). In other words, in the present context, a well-known brand is likely to be positively related to the intention to purchase LED lamps.

\section{Product Availability}

The convenience of purchasing a product or its availability is likely to be a factor in the purchase of a given product. For instance, some studies (Byrne et al., 1991; Davies et al., 1995) have identified that if "green" or organic foods are not available in stores it can be a barrier to their purchase. Moreover, Vermeir and Verbeke (2006) have argued that many consumers have the motivation to purchase "green" products but this often does not translate into purchasing behavior because of low availability. Further, Mainieri et al. (1997) have argued that the reason why consumers' environmental consciousness has lagged behind pro-environmental behavior is because of 
inadequate availability and marketing of environmentally-friendly products. Thus, it is hypothesized that product availability is positively related to the intention to buy LED lamps.

\section{Promotion}

Among the various promotional tools available, it has been found that sales promotions stimulate quick and large purchases during a limited period of time. Thus it can be said such promotions add value to a product (i.e., getting more for less) only for a limited time in order to stimulate consumers' purchase behavior and effective sales, and to create greater effort on the part of the sales force. Promotions can include for example price reductions, free gifts, premiums, contests, exchange offers, rebates and sweepstakes, "buy one, get one free" offers, discounts and points for making purchases, and many other items and activities. Additionally, sellers use such incentive-type promotions for a variety of reasons; for example, to attract new buyers, to reward loyal customers, and to increase the repurchase rates of customers that make purchases only occasionally. Furthermore, sales promotions often attract "brand switchers" that are primarily looking for low prices and good value or premiums. According to Ailawadi, Gedenk, and Neslin (1999) a promotion can even yield a long-term increase in the market share if some individuals try the brand that might not have otherwise done so. Thus, it is hypothesized that promotions are positively related to the intention to purchase LED lamps.

\section{Corporate Social Responsibility}

Consumers and a company's stakeholders become aware of corporate social responsibility (CSR) through a variety of means, such as sustainability reporting, and this, according to Bebbington et al. (2008), can be a way of enhancing a company's reputation. Outstanding corporate reputation, for example, is often related to higher brand value and this may contribute to an increase in a business's success (e.g., Fombrun, 1996). In particular, a company's reputation may be enhanced through the reporting of the successful engagement in non-market matters, for example in social or environmental projects that are not considered a part of the core business activities. Moreover, if a company has a reputation for long-standing commitment to environmental conservation, that company is likely to be considered more trustworthy than its counterparts. It follows then, in the present context, that the higher the corporate social responsibility is perceived to be, the more likely it is that consumers will buy LED lamps from that company.

\section{Personal Characteristics}

\section{Environmental Consciousness}

According to Diekmann and Franzen (1999), a large number of respondents throughout the world have stated that they are very concerned about environmental problems. Customers today are more than ever aware of the seriousness of environmental degradation, and this results in greater ecological consciousness, the favoring of businesses that support environmental practices, and the desire to purchase eco-friendly products and services among other issues (Laroche et al., 2001). Predictably, the level of people's environmental concern is linked to their interest in and willingness to purchase green products (Biswas et al., 2000). Therefore, it is assumed here that environmental consciousness is positively related to the intention to purchase LED lamps.

\section{Social Well-Being}

Energy also of course has strong and important links to the environment, as many energy sources are drawn directly from the environment. This requires the sound management of these sources so that they can be sustainable. On the other hand, energy use also affects the environment; as is well known, emissions from fossil fuels, for example, reach beyond local and national levels to affect the global environment and have been asserted to contribute to changes in the world climates - energy use has environmental impacts regardless of the source or mechanism. For example, hydroelectric projects affect the local ecological systems and have been known to displace long-standing social systems, and it is known that fossil fuel power creates pollution in the extraction, transportation, and combustion of its raw materials. It can be asserted then that efficiency in the use of energy is the ultimate reduction strategy regarding pollution. With reference to the present discussion, the purchase of energy-efficient 
appliances may well reduce this pressure on the environment (public benefit) and may yield private benefits such as reduced expenditure and use of energy. An earlier study by Leelakulthanit (2013) suggests that social well-being might be an explanation of the intention to buy energy-saving lamps in general, and in this study, it is hypothesized that social well-being is positively related to the intention to purchase LED lamps in particular.

\section{Perceived Effectiveness of Environmental Behaviour}

According to Ellen et al. (1991), "perceived consumer effectiveness" refers to the extent to which individuals believe that their actions make a difference in solving a problem. Later, Kim and Choi (2005) argued that individuals acting in consonance with a strong belief that their environmentally-conscious behavior will result in a positive outcome are more likely to engage in the behaviors that support their concern for the environment. Thus, it is hypothesized that perceived consumer effectiveness or the perceived effectiveness of environmental behaviour is positively related to the intention to purchase LED lamps.

\section{Demographic Characteristics}

\section{Gender}

Helping behavior, including behaviors whose intention is to help the environment, can be explained in part using three ecological value orientations: altruistic, egoistic, and biospheric values. The norm-activation model (Schwartz, 1977) and the value-belief-norm theory (Stern et al., 1999) suggest that environmental attitudes, beliefs, and environmental behaviors are shaped by combining these three value orientations. For example, people with an egoistic value orientation are concerned about the environment for their own benefits, while people with an altruistic value orientation are concerned about the environment for the welfare of other people; and those with a biospheric value orientation care about the environment because of its possible impact on ecological systems rather than personal benefits or human survival. Empirical studies have revealed that there are possible gender differences in relation to these three ecological value orientations. Stern et al. (1993), for example, showed that women possessed a stronger inclination toward all three types of value orientation than men. Corroborating this, in a telephone survey of 1,005 California adults, Schultz (2001) found that women scored higher on all three value orientations. Additionally, in a more recent study (Swimi et al., 2010), the women showed higher levels of altruistic and egoistic value orientations. It is hypothesized then that females are more likely to purchase LED lamps than males.

Age

Like gender, the factor of age is also related to the purchase of technology. For example, it has been asserted that households with younger individuals tend to prefer up-to-date technology, which is usually also more energy efficient. Moreover, the survey results of Linden et al. (2006) for Sweden indicate that younger people have better knowledge about energy-efficient measures than older people. Additionally, the studies by Whitehead (1991) and those of Carlsson and Johansson-Stenman (2000) - cited by Torgler and Garçia-Valiñas (2007) — found that people are less willing to pay for environmental protection as they get older. This may be because these individuals expect fewer benefits from environmental preservation since they perceive that they their remaining lifetime is not long.

Torgler and Garçia-Valiñas (2007) in a study on Spain, and Torgler et al. (2008) in a study on 33 Western European countries, also observed a negative correlation between age and environmental attitudes and preferences. Similarly, according to Howell and Laska (1992), younger people in the U.S. are more concerned about the environment than older people. Given the results of these studies then, it is assumed here that age is negatively related to the intention to purchase LED lamps.

\section{Education}

Many studies suggest that there is a positive relation between one's education level and the extent to which he or she engages in energy-saving activities. These studies include the econometric analyses of Hirst and Goeltz 
(1982), Brechling and Smith (1994), and Scott (1997) regarding the adoption of such technology. Among the reasons for the assertion of this positive correlation is that, according to Schultz (1995), education reduces the costs of acquiring information. In addition to this, other factors have been found to be positively related to education, for example, attitudes toward the environment, concepts of social status and one's lifestyle (Lutzenhiser, 1993; Weber \& Perrels, 2000), and belonging to a particular social group that approves environmentally-friendly behavior. Authors Torgler and Garçia-Valiñas (2007, p. 538) cite several sources in their work that suggests that higher education levels are associated with greater concern about environmental conservation. It follows then in the present context that education can be hypothesized as being positively related to the intention to purchase LED lamps.

\section{Household Income}

In addition to the above-discussed factors, household income, according to Held (1983), can be seen as a dominant predictor of behaviors regarding the use of energy. In an econometric estimation of the determinants of energy conservation expenditures, Long (1993) proved that the "income level of the households was positively and statistically related to larger conservation investments." Along the same lines, Kasulis et al. (1981) argued that if a household belongs to a low income group, the individuals in it are already likely to be using low amounts of energy and for this reason would not be likely to respond to requests to conserve energy to a greater extent. Additionally, Stern and Gardner (1981) stressed that it is energy efficiency rather than measures that curtail its use that is preferred by higher-income consumers. In a recent study, Poortinga et al. (2003) argued that higher-income groups were more open to the idea of technical improvements; for these individuals, behavioural measures were the least acceptable, perhaps because new technical measures often require an initial investment, and this might be less problematic for them. It must be borne in mind that there is often a long pay-back period for conservation-related activities, and for this reason, according to Schipper and Hawk (1991), low-income households may feel financially unstable and lack the capital to invest in residential energy-efficient improvements. Finally, Walsh's (1989) econometric analysis confirmed that "higher-income households are better able than lower-income families" to purchase technology that supports or encourages energy conservation. Thus, it is hypothesized that household income is positively related to the intention to purchase LED lamps.

\section{METHODOLOGY}

\section{Sampling}

The questionnaire was first tested with $37 \mathrm{MBA}$ students for a preliminary understanding of the content. This was followed with pretests where 37 eligible adult shoppers were interviewed that were the decision makers and at least 18 years old. The questionnaire was revised based on the feedback of the interviewees for its suitability and clarity. Then, the main study was conducted. It was done by interviewing 555 eligible shoppers at 37 randomlyselected shopping centers in Bangkok. At this stage, the eligible shoppers were also those that were aware of LED lamps. The rate of unawareness of LED lamps turned out to be $13.03 \%$ and the response rate was $71.70 \%$.

\section{Data Analysis}

Price, the perceived benefits of LED lamps (namely, quality, energy savings, and durability), the trustworthiness of LED lamp performance, the compatibility of LED lamps with lighting fixtures, the marketing of LED lamps (namely, brand, availability, promotion, and CSR), and consumer characteristics, including environmental consciousness, social well-being, and effectiveness of environmental behavior, as well as demographic characteristics, including gender, age, education, and household income, are likely to be positively related to the intention to buy LED lamps. In order to find out whether this hypothesis was true, a multiple regression analysis was conducted. Specifically, the earlier-mentioned independent variables were regressed on the intention to buy LED lamps, which was taken as the dependent variable. The results of the multiple regression analysis are shown in Table 1. 
Table 1: Results of the Multiple Regression Analysis of the Intention to Buy LED Lamps and the Relative Advantage, Marketing Factors, Personal Characteristics, and Demographic Characteristics of the Whole Sample

\begin{tabular}{|c|c|c|c|c|c|c|c|}
\hline \multirow[t]{2}{*}{ Model } & \multicolumn{2}{|c|}{$\begin{array}{c}\text { Unstandardized } \\
\text { Coefficients }\end{array}$} & \multirow{2}{*}{$\begin{array}{c}\begin{array}{c}\text { Standardized } \\
\text { Coefficients }\end{array} \\
\text { Beta }\end{array}$} & \multirow[t]{2}{*}{$\mathbf{t}$} & \multirow[t]{2}{*}{ Sig. } & \multicolumn{2}{|c|}{$\begin{array}{c}\text { Collinearity } \\
\text { Statistics }\end{array}$} \\
\hline & B & Std. Error & & & & Tolerance & VIF \\
\hline (Constant) & .406 & .543 & & .747 & .455 & & \\
\hline price & .003 & .031 & .004 & .101 & .920 & .929 & 1.076 \\
\hline quality & .101 & .065 & .085 & 1.552 & .121 & .528 & 1.893 \\
\hline energy saving & .203 & .064 & .175 & 3.168 & $.002 *$ & .517 & 1.936 \\
\hline durability & -.075 & .066 & -.062 & -1.133 & .258 & .530 & 1.886 \\
\hline trust in performance & .052 & .057 & .047 & .903 & .367 & .590 & 1.694 \\
\hline compatibility with lighting fixtures & -.019 & .047 & -.020 & -.410 & .682 & 691 & 1.448 \\
\hline brand & -.002 & .046 & -.002 & -.038 & .970 & .711 & 1.406 \\
\hline availability & .126 & .050 & .119 & 2.532 & $.012 *$ & .705 & 1.418 \\
\hline promotion & -.018 & .036 & -.022 & -.495 & .621 & .780 & 1.282 \\
\hline CSR & .093 & .039 & .115 & 2.393 & $.017 *$ & 675 & 1.482 \\
\hline environmental conscious & .027 & .078 & .021 & .347 & .729 & .410 & 2.437 \\
\hline social well_being & .064 & .077 & .048 & .837 & .403 & .481 & 2.081 \\
\hline effectiveness of env.behavior & .131 & .064 & .113 & 2.067 & $.039 *$ & .526 & 1.902 \\
\hline gender & -.085 & .106 & -.033 & -.808 & .419 & .963 & 1.038 \\
\hline age & .000 & .005 & -.002 & -.053 & .958 & .928 & 1.078 \\
\hline educ group & -.072 & .140 & -.021 & -.517 & .606 & .924 & 1.083 \\
\hline income group & .218 & .124 & .073 & 1.752 & $.080 *$ & .911 & 1.098 \\
\hline
\end{tabular}

$\mathrm{R}^{2}=.182 ; \mathrm{R}^{2}=.155 ; \mathrm{F}_{17,521}=6.799 ; \mathrm{P}=.000 ; *=$ Significant at $\alpha \leq .1$

\section{RESULTS AND DISCUSSION}

According to the standardized beta coefficients, as shown in Table 1, the positive determinants of the intention to buy LED lamps in the whole sample were energy savings, product availability, CSR, effectiveness of environmental behavior, and household income respectively. In other words, energy savings tended to influence the intention to buy LED lamps the most, followed by the marketing factors of product availability and CSR, then by the effectiveness of environmental behavior, and least influenced by household income. The factors affecting the adoption of LED lamps as indicated by the significance of the regression coefficients better reflected the reality than those accessed by the method of direct questioning of such factors because it helps to avoid the error of social desirability bias.

Household income was found to be a significant determinant of the intention to buy LED lamps perhaps because obviously, the high household income people are more able to pay for the generally much more expensive LED lamps as compared to ordinary lamps than the low household income persons. However, the deeper motivation for buying LED lamps has to be investigated further. Toward this end, two other similar multiple regressions to the whole sample were run. One was for the low household income group. Another one was for the high household income group. In this study, the low household income group consisted of the people that had a household income less than 36,000 Baht per month, whereas the high household income group was comprised of the persons that had household income of at least 36,000 Baht per month. 
Table 2: Results of the Multiple Regression Analysis of the Intention to Buy LED Lamps and the Relative Advantage, Marketing Factors, Personal Characteristics, and Demographic Characteristics in the Low Household Income Group

\begin{tabular}{|c|c|c|c|c|c|c|c|}
\hline \multirow{2}{*}{ Model } & \multicolumn{2}{|c|}{$\begin{array}{l}\text { Unstandardized } \\
\text { Coefficients }\end{array}$} & \multirow{2}{*}{$\begin{array}{c}\begin{array}{r}\text { Standardized } \\
\text { Coefficients }\end{array} \\
\text { Beta }\end{array}$} & \multirow{2}{*}{$\mathbf{t}$} & \multirow{2}{*}{ Sig. } & \multicolumn{2}{|c|}{ Collinearity Statistics } \\
\hline & B & Std. Error & & & & Tolerance & VIF \\
\hline (Constant) & 1.371 & .896 & & 1.531 & .128 & & \\
\hline price & -.043 & .065 & -.059 & -.670 & .504 & .737 & 1.356 \\
\hline quality & .276 & .129 & .253 & 2.139 & $.034 *$ & .402 & 2.486 \\
\hline energy saving & .124 & .112 & .123 & 1.108 & .270 & .461 & 2.170 \\
\hline durability & -.099 & .131 & -.085 & -.752 & .454 & .435 & 2.297 \\
\hline trust in performance & .124 & .104 & .127 & 1.197 & .234 & .501 & 1.997 \\
\hline compatibility with lighting fixtures & -.261 & .094 & -.276 & -2.768 & $.007 *$ & .565 & 1.769 \\
\hline brand & .055 & .089 & .058 & .620 & .536 & .636 & 1.572 \\
\hline availability & .160 & .086 & .170 & 1.866 & $.064 *$ & 679 & 1.472 \\
\hline promotion & -.073 & .077 & -.092 & -.945 & .347 & .592 & 1.689 \\
\hline CSR & .232 & .081 & .310 & 2.866 & $.005^{*}$ & .482 & 2.074 \\
\hline environmental conscious & .228 & .183 & .189 & 1.250 & .214 & .245 & 4.081 \\
\hline social well_being & -.026 & .148 & -.021 & -.177 & .860 & .410 & 2.440 \\
\hline effectiveness of env.behavior & -.103 & .154 & -.092 & -.669 & .505 & .300 & 3.336 \\
\hline gender & -.214 & .216 & -.080 & -.989 & .325 & .868 & 1.152 \\
\hline age & -.004 & .012 & -.027 & -.322 & .748 & .827 & 1.209 \\
\hline educ group & -.083 & .240 & -.029 & -.345 & .731 & .794 & 1.260 \\
\hline
\end{tabular}

$\mathrm{R}^{2}=.318 ; \mathrm{R}^{2}=.228 ; \mathrm{F}_{16,121}=3.533 ; \mathrm{P}=.000 ; *=$ Significant at $\alpha \leq .1$

The results of the multiple regression of the low household income group as shown in Table 2 indicate that the strongest driving force for adopting LED lamps in the low household income group was CSR, followed by the compatibility of LED lamps with lighting fixtures and quality; the weakest driving force was product availability. It is noteworthy that the compatibility of LED lamps with lighting fixtures works contrary to the adoption of LED lamps. This may mean that in the case of high compatibility of LED lamps with lighting fixtures, there will be no need to change the light to be LED lamps. If there is no compatibility between LED lamps and the lighting fixtures, the low household income people may be forced to change to the totally new LED set according to the trend. Marketing forces are likely to work for the low household income segment and are led by CSR. This suggests that the corporate image of social responsibility does count for consumers. The company that has genuine interests in public welfare, whether it be the social aspect of life or the environmental aspect of life, tends to get support by the consumers than the company that stands behind profit alone. That is to say, the consumers may consider the company which is socially responsible first; then they seem to consider the product quality and its availability afterwards because they cannot afford to use low-quality products or struggle in order to purchase the products. This means that the company cannot stand behind the profit without offering quality products which are easily accessible to the low household income segment.

The results of the multiple regression of the high household income group as shown in Table 3 indicate that the strongest driving force for adopting LED lamps in this group was energy savings, followed by the perceived effectiveness of environmental behavior. Taken together, it becomes clear that the high household income segment wants to help solve the natural resource problem by buying LED lamps, which has the property of saving energy. It should be noted that high household income people are equally environmentally conscious and perceive that their environmental behavior is effective as well, with the mean value of 5.58. However, being green does not play an important role in the adoption of LED lamps, let alone the eagerness to help solve the energy sufficiency problem. The reason may be that buying energy-saving LED lamps is a direct way of solving the problem of rapidly-depleting energy resources, whereas the benefit of environmental conservation due to energy savings seems to be seen as a byproduct. 
Table 3: Results of the Multiple Regression Analysis of the Intention to Buy LED Lamps and the Relative Advantage, Marketing Factors, Personal Characteristics, and Demographic Characteristics in the High Household Income Group

\begin{tabular}{|c|c|c|c|c|c|c|c|}
\hline \multirow[t]{2}{*}{ Model } & \multicolumn{2}{|c|}{$\begin{array}{c}\text { Unstandardized } \\
\text { Coefficients }\end{array}$} & \multirow{2}{*}{$\begin{array}{c}\begin{array}{c}\text { Standardized } \\
\text { Coefficients }\end{array} \\
\text { Beta } \\
\end{array}$} & \multirow[t]{2}{*}{$\mathbf{t}$} & \multirow[t]{2}{*}{ Sig. } & \multicolumn{2}{|c|}{ Collinearity Statistics } \\
\hline & B & Std. Error & & & & Tolerance & VIF \\
\hline (Constant) & .586 & .716 & & .819 & .413 & & \\
\hline price & .012 & .036 & .016 & .323 & .747 & .938 & 1.066 \\
\hline quality & .037 & .078 & .030 & .471 & 638 & .548 & 1.824 \\
\hline energy saving & .248 & .080 & .202 & 3.110 & $.002 *$ & .523 & 1.913 \\
\hline durability & -.062 & .078 & -.050 & -.801 & .424 & .554 & 1.806 \\
\hline trust in performance & .011 & .070 & .010 & .161 & .872 & .610 & 1.638 \\
\hline compatibility with lighting fixtures & .058 & .056 & .057 & 1.032 & .303 & .708 & 1.412 \\
\hline brand & -.022 & .054 & -.022 & -.404 & .687 & .727 & 1.376 \\
\hline availability & .100 & .063 & .091 & 1.590 & .113 & .670 & 1.492 \\
\hline promotion & .001 & .041 & .001 & .016 & .988 & .799 & 1.252 \\
\hline CSR & .057 & .046 & .069 & 1.232 & .219 & .692 & 1.446 \\
\hline environmental conscious & .016 & .088 & .012 & .178 & .859 & .456 & 2.193 \\
\hline social well_being & .089 & .091 & .065 & .978 & .329 & .496 & 2.016 \\
\hline effectiveness of env.behavior & .169 & .072 & .145 & 2.359 & $.019 *$ & .584 & 1.713 \\
\hline gender & -.040 & .122 & -.016 & -.326 & .744 & .967 & 1.034 \\
\hline age & .001 & .005 & .009 & .181 & .856 & .932 & 1.074 \\
\hline educ group & -.071 & .180 & -.019 & -.392 & .696 & .973 & 1.028 \\
\hline
\end{tabular}

$\mathrm{R}^{2}=.157 ; \mathrm{R}^{2}=.122 ; \mathrm{F}_{16,384}=4.461 ; \mathrm{P}=.000 ; *=$ Significant at $\alpha \leq .05$

In order to assess the appropriateness of the marketing performances in the current situation, the notion of importance-performance is compared between the low household income segment and the high household income segment. According to the t-test of the low versus high household income group, it was found that for all of the important factors affecting the adoption of LED lamps, namely, CSR, compatibility of LED lamps with lighting fixtures, quality, and product availability, there was only one difference in performance between the low household income group and the high household income group. Specifically, the low-income household group perceives that the LED lamp considered for the next purchase has lower quality than that perceived by the high household income group. This means that somehow the marketing effort in promoting the quality of LED lamps has underdone in the low household income segment but overdone in the high income segment. Similarly, when the high household income segment is taken as a frame of reference in comparing the importance-performance aspects of the factors affecting the adoption of LED lamps, it was found that perceived effectiveness of environmental behavior in the high household income group was not significantly different than that in the low household income group in spite of its importance to the high household income segment. This suggests that somehow marketers may not be doing an adequate job in informing the high household income consumers about the impact of using energy-saving LED lamps as a way of solving the energy sufficiency problem.

\section{CONCLUSIONS AND MANAGERIAL IMPLICATIONS}

In the case of the early stage of the diffusion of LED lamps, which is an innovation, it was found that the relative advantage was not a significant factor in their adoption because price is not an important determinant of their adoption. Further, the benefits of energy savings become the sole determinant of their adoption of the entire sample. For the low household income segment, the benefit that functions as a driving force for the adoption of LED lamps is quality, whereas for the high household income group it was energy savings. This implies that the product development of LED lamps in terms of quality and energy saving improvements is needed in order to enhance the adoption rate of LED lamps.

CSR tends to play the most significant role in the adoption of LED lamps for the low household income group. This may be because at the back of the low household income people's mind, they may think that it is useless for them to be a good citizen through buying LED lamps without the corporations' initiative in taking charge as good corporate citizens by embracing the CSR notion first. In other words, businesses should go green first. In encouraging the buying of LED lamps for the low income household segment, it is also important that the products be widely available. This suggests that the companies may want to distribute their products through highlyaccessible outlets, for instance, convenience stores. 
In addition to the energy savings benefit of LED lamps, the belief that one can help solve natural resource problems by saving energy is a driving force for the adoption of LED lamps in the high household income segment. These two motivators for the adoption of LED lamps tend to go hand-in-hand. It is likely that the high household income people perceive that simply buying LED lamps can already help solve the energy sufficiency problem. This is a convenient solution for the well-to-do people that can afford to buy LED lamps instead of buying cheaper incandescent lamps. The implication is that the well-to-do persons should be informed through various media that have a good reach to this segment concerning the impact of using energy-saving LED lamps on scarce energy resources. Persuading this segment to buy LED lamps is not necessary because of their self-motivated characteristics of solving energy problems by saving energy - they simply want to know the important facts. It follows that scientific and related knowledge about energy savings and its impact can be disseminated through the classes through teaching as well.

\section{AUTHOR INFORMAITON}

Dr. Orose Leelakulthanit is an associate professor of marketing at the NIDA Business School, National Institute of Development Administration, Bangkok, Thailand. Her academic research has been in marketing and consumer behavior. Her main research interests include quality of life issues and sustainable consumption. E-mail: orose@nida.ac.th

\section{REFERENCES}

1. Ailawadi, K., Gedenk, K., \& Neslin, S. A. (1999). Heterogeneity and purchase event feedback in choice models: An empirical analysis with implications for model building. International Journal of Research in Marketing, 16(3), 177-98.

2. Bebbington, J., Larrinaga, C., \& Moneva, J. M. (2008). Corporate social reporting and reputation risk management. Accounting, Auditing and Accountability Journal, 21(3), 337-361.

3. Bellman, J. R., \& Park, C. W. (1980). Effects of prior knowledge and experience and phase of the choice process on consumer decision process: A protocol analysis. Journal of Consumer Research, 7(3), 234-248.

4. Biswas, A. et al. (2000). The recycling cycle: An empirical examination of consumer waste recycling and recycling shopping behaviors. Advertisement and Environmental Issues, 19(1), 93-115.

5. $\quad$ Brechling, V., \& Smith, S. (1994). Household energy efficiency in the UK. Fiscal Studies, 15(2), 4456.

6. Barr, S., Gilg, A. W., \& Ford, N. (2005). The household energy gap: Examining the divide between habitual-and purchase-related conservation behaviours. Energy Policy, 33(11), 1425-1444.

7. Byrne, P. J., Toensmeyer, U. C., German, C. L., \& Muller, H. R. (1991). Analysis of consumer attitude toward organic produce purchase likelihood. Journal of Food Distribution Research, 22(2), 49-62.

8. Carlsson, F., \& Johansson-Stenman, O. (2000). Willingness to pay for improved air quality in Sweden. Applied Economics, 32(6), 661-669.

9. Davies, A., Titterington, A. J., \& Cochrane, C. (1995). Who buys organic food? A profile of the purchasers of organic food in Northern Ireland. British Food Journal, 97(10), 17-23.

10. Diekmann, A., \& Franzen, A. (1999). The wealth of nations and environmental concern. Environment and Behavior, 31(4), 540-549.

11. Ellen, P. S., Wiener, J. L., \& Cobb-Walgren, C. (1991). The role of perceived consumer effectiveness in motivating environmentally conscious behaviours. Journal of Public Policy and Marketing, 10(2), 102-117.

12. Fombrun, C. (1966). Reputation: Realizing value from the corporate image. Boston: Harvard Business Press.

13. Held, M. (1983). Social impacts of energy conservation. Journal of Economic Psychology, 3(3-4), 379-394.

14. Henard, D. H., \& Szymanski, D. M. (2001). Why some new products are more successful than others. Journal of Marketing Research, 38(3), 362-375.

15. Hirst, E., \& Goeltz, R. (1982). Residential energy conservation actions: Analysis of disaggregated data. Energy Systems and Policy, 6, 135-150.

16. Howell, S. E., \& Laska, L. B. (1992). The changing face of the environmental coalition: A research note. Environment and Behavior, 24(1), 134-144.

17. Jacoby, J., Syzabillo, G. J., \& Busato-Schach, J. (1977). Information acquisition behavior in brand choice situations. Journal of Consumer Research, 3(4), 209-216. 
18. Kasulis, J., Huettener, D., \& Dikeman, N. (1981). The feasibility of changing electricity consumption patterns. Journal of Consumer Research, 8(3), 279-290.

19. Kim, Y., \& Choi, S. R. (2005). Antecedents of green purchase behaviour: An examination of collectivism, environmental concern and PCE. Advances in Consumer Research, 32(1), 592-599.

20. Laroche, M., Begeron, J., \& Barbaro-Forleo, G. (2001). Targeting consumers who are willing to pay more for environmentally friendly products. Journal of Consumer Marketing, 18(6), 503-520.

21. Leelakulthanit, O. (2013). The relationship of sustainable consumption and life satisfaction. Journal of Business Management and Administration, 1(1), 1-8.

22. Linden, A-L., Carlsson-Kanyama, A., \& Riksson, B. (2006). Efficient and inefficient aspects of residential energy behaviour: What are the policy instruments for change? Energy Policy, 34(14), 1918-1927.

23. Long, J. (1993). An econometric analysis of residential expenditures on energy conservation and renewable energy sources. Energy Economics, 15(4), 232-238.

24. Lutzenhiser, L. (1993). Social and behavioral aspects of energy use. Annual Review of Energy and Environment, 18(1), 247-289.

25. Mainieri, T., Barnett, E. G., Unipan, J. B., \& Oskamp, S. (1977). Green buying: The influence of environmental concern on consumer behavior. The Journal of Social Psychology, 137(2), 189-204.

26. Menanteau, P., \& Lefebvre, H. (2000). Competing technologies and the diffusion of innovations: The emergence of energy-efficient lamps in the residential sector. Research Policy, 29(3), 375-389.

27. Mostafa, M. (2009). Shades of green: A psychographic segmentation of the green consumer in Kuwait using self-organizing maps. Expert Systems with Applications, 36(8), 11030-11038.

28. Poortinga, W., Steg, L., Vleg, C., \& Wiesma, G. (2003). Household preferences for energy-saving measures: A conjoint analysis. Journal of Economic Psychology, 24(1), 49-64.

29. Schipper, L., \& Hawk, D. (1991). More efficient household electricity use. Energy Policy, 19(3), $244-$ 265.

30. Schultz, P. W. (2001). The structure of environmental concern: Concern for self, other people, and the biosphere. Journal of Environmental Psychology, 21(4), 327-339.

31. Schultz, T. W. (1975). The value of the ability to deal wit disequilibrium. Journal of Economic Literature, 13(3), 827-46.

32. Schwartz, S. H. (1977). Normative influences on altruism. In Berkowitz, L. (Ed.), Advances in Experimental Social Psychology, 10, 221-279. New York: Academic Press.

33. Scott, S. (1997). Household energy efficiency in Ireland: A replication study of ownership of energy saving items. Energy Economics, 19(2), 187-208.

34. Stern, P., \& Gardner, G. (1981). Psychological research and energy policy. American Psychologist, 36(4), 329-342.

35. Stern, P. C., Dietz, T., \& Kalof, L. (1993). Value orientations, gender, and environmental concern. Environment and Behavior, 25(5), 322-348.

36. Stern, P. C., Dietz, T., Abel, T., Guagnano, G. A., \& Kalof, L. (1999). A value-belief norm theory of support for social movements: The case of environmentalism. Research in Human Ecology, 6(2), 81-97.

37. Swimi, V., Chamorro-Premuzic, T., Snelgar, R., \& Furnham, A. (2010). Egoistic, altruistic, and biospheric environmental concerns: A path analytic investigation of their determinants. Scandinavian Journal of Psychology, 51(2), 139-145.

38. Torgler, B., \& García-Valiñas, M. A. (2007). The determinants of individuals' attitudes towards preventing environmental damage. Ecological Economics, 63(2-3), 536-552.

39. Torgler, B., García-Valiñas, M. A., \& Macintyre, A. (2008). Differences in preferences towards the environment: The impact of a gender, age and parental effect. (Working Paper). School of Economics and Finance, Queensland University of Technology, Australia.

40. Vermeir, I., \& Verbeke, W. (2006). Sustainable food consumption: Exploring the consumer "attitudebehavioral intention" gap. Journal of Agriculture \& Environmental Ethics, 19(2), 169-194.

41. Walsh, M. (1989). Energy tax credits and housing improvement. Energy Economics, 11(4), $275-284$.

42. Weber, C., \& Perrels, A. (2000). Modelling lifestyle effects on energy demand and related emissions. Energy Policy, 28(8), 549-566.

43. Whitehead, J. C. (1991). Environmental interest group behaviour and self-selection bias in contingent valuation mail surveys. Growth and Change, 22(1), 10-21. 
NOTES 